\title{
The role of chemosensitive afferent nerves and TRP ion channels in the pathomechanism of headaches
}

\author{
Mária Dux • Péter Sántha • Gábor Jancsó
}

Received: 6 July 2012 / Accepted: 25 July 2012 /Published online: 9 August 2012

(C) Springer-Verlag 2012

\begin{abstract}
The involvement of trigeminovascular afferent nerves in the pathomechanism of primary headaches is well established, but a pivotal role of a particular class of primary sensory neurons has not been advocated. This review focuses on the evidence that supports the critical involvement of transient receptor potential (TRP) channels in the pathophysiology of primary headaches, in particular, migraine. Transient receptor potential vanilloid 1 and transient receptor potential ankyrin 1 receptors sensitive to vanilloids and other irritants are localized on chemosensitive afferent nerves, and they are involved in meningeal nociceptive and vascular responses involving neurogenic dural vasodilatation and plasma extravasation. The concept of the trigeminal nocisensor complex is put forward which involves the trigeminal chemosensitive afferent fibers/neurons equipped with specific nocisensor molecules, the elements of the meningeal microcirculatory system, and the dural mast cells. It is suggested that the activation level of this complex may explain some of the specific features of migraine headache. Pharmacological modulation of TRP channel function may offer a novel approach to the management of head pain, in particular, migraine.
\end{abstract}

Keywords TRPV1 - TRPA1 - Meningeal blood flow · Headache $\cdot$ Dura mater

\section{Introduction}

Headaches, in particular, migraine, belongs to the most frequent pains for which patients seek medical attention.

M. Dux $(\bowtie) \cdot$ P. Sántha $\cdot$ G. Jancsó

Department of Physiology, University of Szeged,

Dóm tér 10.,

6720 Szeged, Hungary

e-mail: dux.maria@med.u-szeged.hu
The mechanisms of migraine headaches are still incompletely understood, but they involve both neurogenic and vascular pathologies of the meninges. Theories focusing either on the vascular or central and peripheral neuronal processes have been evolved which could explain some but not all fundamental aspects of this pain disorder. The functional properties and electrophysiological traits of meningeal primary afferents have also been characterized in great detail, but a pivotal role of a particular class of primary afferent neurons has not been advocated. In recent years, the role of transient receptor potential (TRP) channels in the pathophysiology of different pain disorders has been well established [11, 40, 98]. The existence and functional significance of meningeal chemosensitive primary afferent nerves, which are sensitive to vanilloids and other irritants and express the transient receptor potential vanilloid 1 (TRPV1) and the transient receptor potential ankyrin 1 (TRPA1) receptors, are now well-documented [34, 96, 116]. Since in most organs and tissues of the body TRP ion channels are intimately involved in the mediation of noxious events [16, 26, 67, 73, 95], this review focuses on the evidence that support the critical involvement of TRPV1 and TRPA1 channels in the pathophysiology of primary headaches, in particular, migraine.

\section{Nerves and neuroreceptors of the dura mater encephali}

Classical anatomical and functional studies have revealed some of the most important aspects of headache mechanisms. Investigations into the origin of intracranial pain suggested that the dura mater encephali is the main, and probably the only, pain-sensitive structure within the cranium $[44,106]$. Topographical analysis of the localization of "pain receptors" also disclosed that almost exclusively the paravascular regions of the dura mater but not areas remote 
from the larger blood vessels are sensitive to painful stimulation [102]. Anatomical studies demonstrated the distribution of sympathetic and trigeminal sensory nerves within the dura mater of several mammalian species, including man $[2$, $46,70,91,92]$. The dura mater is densely innervated by both sympathetic and sensory nerves, which run freely in the dural stroma or are clearly associated with meningeal arteries and veins. Chemical neuroanatomical studies disclosed the various populations of meningeal nerves containing classical transmitters such as noradrenaline and the peptides substance P (SP), neurokinin A (NKA), and calcitonin generelated peptide (CGRP) [18, 38, 125]. Most of these mediators are contained in unmyelinated axons, but electron microscopy revealed large numbers of myelinated nerve fibers, too [2]. Electrophysiological studies have revealed specific populations of dural sensory nerve fibers, many of which showed response properties characteristic of nociceptive afferents [120]. The majority of these nociceptive afferents responded to noxious mechanical stimuli but also to chemical agents, such as capsaicin $[119,121]$. Sensitivity to capsaicin is a fundamental feature of nociceptive afferent fibers, which express the archetypical nociceptive ion channel, the TRPV1 receptor $[17,59,61]$. The existence of unmyelinated capsaicin-sensitive afferent nerves in the rat dura mater has been also demonstrated in electron microscopic studies utilizing an experimental neuroanatomical technique making use of the selective neurotoxic action of capsaicin $[34,72]$. Retrograde labelling combined with immunohistochemistry demonstrated many TRPV1immunoreactive trigeminal ganglion neurons that innervate the dura mater [116]. In addition, immunohistochemical findings furnished direct evidence for a dense innervation of the rat dura mater by TRPV1-immunoreactive paravascular and stromal nerve fibers [36]. Immunohistochemical studies have further characterized the chemical phenotypes of dural afferent fibers and revealed a subpopulation of TRPV1-immunoreactive nerves, which also showed proteinase-activated receptor-2 (PAR-2)-immunoreactivity. Dural mast cells localized, in part, in the close vicinity of blood vessels and also of afferent nerves displayed strong PAR-2-immunoreactivity, too [36, 128]. Recently, another member of the TRP receptor superfamily, the TRPA1, has also been found to be functional on trigeminal dural afferent nerves $[76,96]$. The available experimental evidence suggests that TRPA1 receptors are expressed in chemosensitive primary afferent neurons that are peptidergic and also express the TRPV1 receptor $[62,66,76,118]$.

Although most studies dealing with headache mechanisms in the context of neurogenic inflammation considered the involvement of peptidergic primary afferent neurons which express the TRPV1 receptor, it should be emphasized that a large population of TRPV1-expressing neurons are not peptidergic $[19,105]$. Non-peptidergic nociceptive primary sensory neurons may be identified through their binding of the plant lectin, Griffonia simplicifolia isolectin B4 (IB4). The possible significance of non-peptidergic nociceptive afferents as regards the pathomechanism of headaches has been rarely addressed. It is conceivable that these non-peptidergic TRPV1-expressing nerves do not contribute to local neurogenic vascular reactions, but they provide a parallel afferent pathway for the transmission of nociceptive signals. Although available evidence indicates that the IB4positive and the IB4-negative subpopulations of TRPV1expressing sensory ganglion neurons also show distinct functional characteristics [82, 113], especially under inflammatory conditions [12, 49], the significance of a possible parallel processing of dural nociceptive information remains to be elucidated.

\section{The concept of the trigeminovascular nocisensor complex}

The exact mechanisms of the generation of primary headaches like migraine are still unclear, but apparently, they involve both neurogenic and vascular events. Whereas cortical spreading depression is believed to play an important role in the development of migraine aura [78, 115, 129], the pathophysiological changes in the trigeminovascular system are considered to be of fundamental importance in the generation and maintenance of headache pain. Dysfunctions of the peripheral and/or the central components of the trigeminal nociceptive pathway may be responsible for the generation of intracranial pain and changes in blood flow in headache patients $[5,10,13,20,90]$. Many, but not all, trigeminovascular afferents contain vasoactive peptides, such as SP and CGRP. These peptides contained in primary sensory neurons serve not only as transmitters at the central synapses of nociceptive afferents $[32,56,79]$, but they also play a pivotal role in the mechanisms of the neurogenic inflammatory response originally described in exteroceptive innervation territories (for reviews, see [23, 64, 87]). This unique neurovascular reaction has two components, neurogenic vasodilatation mediated through CGRP and neurogenic plasma extravasation mediated by SP. Neurogenic inflammation is a sterile inflammatory reaction brought about by the release of CGRP, SP, and probably NKA from sensory nerve endings as a consequence of antidromic or orthodromic stimulation of nociceptive afferent nerves [42, $48,60,61,103,112]$. The biological significance of neurogenic inflammation is somewhat obscure and may differ in different organ systems and tissues, but a protective role of sensory neurogenic vasodilatation seems obvious [6]. An increase of blood flow in tissues flooded with microbial products and/or inflammatory mediators may promote the removal of noxious agents and help to restore tissue 
homeostasis. Tissue reactions related to neurogenic inflammation have been shown to aggravate or attenuate tissue injury $[31,41,50,63,64,68]$. In the dura mater, induction of a neurogenic inflammatory response through electrical stimulation of chemosensitive trigeminal afferents has been shown to produce an increase in vascular permeability that could be prevented by depletion of chemosensitive afferents and/or sensory neuropeptides by prior capsaicin desensitization [14]. The significance of neurogenic plasma extravasation as regards migraine pathogenesis in humans is controversial [127]. Clinical studies suggested that a migraine attack can neither be alleviated nor prevented by neurokinin antagonists. Hence, neurogenic plasma extravasation was suggested to be of minor significance as a pathogenetic factor of migraine [29], although more recent studies have demonstrated an increase in meningeal blood vessel permeability during migraine aura in humans [57]. In contrast, neurogenic sensory vasodilatation mediated also by peptide, in particular CGRP, release from chemosensitive afferents appears to play an important role in the pathomechanism of migraine. Its release into the jugular blood has been demonstrated during migraine attacks in humans [52], and, importantly, non-peptide CGRP antagonists have been shown to alleviate migraine headache $[39,101,110]$.

Animal models of intracranial pain and headaches have also provided valuable data on the mechanisms of meningeal sensory neurogenic vasodilatation. Electrical stimulation of meningeal nerves produces vasodilatation in dural blood vessels, which is mediated by the release of CGRP from sensory nerves [77]. This was supported by the findings that both peptide and non-peptide CGRP antagonists inhibited meningeal neurogenic vasodilatation [94, 122]. Prior treatment of the animals with capsaicin greatly reduced or even completely abolished dural neurogenic vasodilatation due to the depletion of sensory neuropeptides and/ or afferent nerves $[34,35]$. Importantly, capsaicin, the archetypical TRPV1 agonist also evoked an increase in meningeal blood flow after local application in a rat open cranial window model of migraine headache. This vasodilatory response was abolished through prior capsaicin desensitization and by capsazepine, a TRPV1 antagonist [34]. These findings indicated that meningeal neurogenic vasodilatation is mediated through the activation of chemosensitive afferent nerves, which are sensitive to capsaicin and express the TRPV1 ion channel. The involvement of this particular class of sensory nerves in meningeal neurogenic plasma extravasation and activation of trigeminovascular nociceptive afferents is also well established [89]. Hence, activation of second-order neurons of the trigeminal nucleus caudalis by meningeal application of capsaicin or other chemical agents was inhibited after neonatal or systemic administration of capsaicin as assessed with the c-fos technique [99]. Electron microscopic and immunohistochemical data furnished direct evidence for the existence and distribution of unmyelinated capsaicin-sensitive TRPV1 immunoreactive sensory nerve fibers in the rat dura mater [34-36, 116]. Investigations into the significance of chemosensitive afferent nerves in meningeal vascular reactions have also revealed that at least a subpopulation of these particular afferents express the PAR2 receptor, the activation of which elicits vasodilatation [36]. PAR-2 activation-induced vasodilatation is mediated by CGRP and a pathway involving nitric oxide $[36,37]$. The activation of PAR-2 receptors localized on meningeal chemosensitive afferent nerves may be brought about by proteolytic enzymes, e.g., by tryptase released from activated mast cells. Activation of mast cells has been shown after electrical or chemical stimulation of dural afferent nerves, and it is believed to modulate the neurogenic inflammatory response [30]. This assumption is supported by the findings, which demonstrated that activation of PAR-2 induced sensitization of the TRPV1 receptor [36]. These observations suggest that PAR-2-mediated activation and sensitization of meningeal chemosensitive $\mathrm{C}$-fiber nociceptors may significantly contribute to the pathophysiology of headaches.

Considering the possible mechanisms that may operate to maintain headache pain, a complex interplay among the different pain-producing agents implicated in meningeal nociception should be taken into account. Stimulation of chemosensitive afferent nerves, e.g., through activation of the TRPV1 receptors by inflammatory mediators, such as bradykinin, prostanoids, endovanilloids, and low $\mathrm{pH}$, characteristic of inflammatory exudates, induces a CGRP-mediated marked increase in meningeal blood flow locally and activation of second order neurons in the caudal trigeminal nucleus centrally [80]. Similarly, activation of the TRPA1 receptors by, e.g., environmental irritants results in the release of CGRP from the dura mater and may also produce head pain $[76,96]$. The activation of meningeal chemosensitive afferents also leads to the release of vasoactive tachykinins, SP, and NKA, which may elicit an increase in vascular permeability and moderate vasodilatation, too. Tachykinins and CGRP may affect meningeal mast cells resulting in the release of mast cell constituents and mediators, such as histamine and the proteolytic enzyme, tryptase [65, 81]. These, in turn, may further activate meningeal chemosensitive nociceptors resulting in additional neuropeptide release and central activation. Moreover, activation of neuronal PAR-2 receptors produces sensitization of the TRPV1 receptor [36], resulting in a further increase in dural blood flow. At present, it is unclear whether axon reflex mechanisms are involved in meningeal nociceptive functions, but previous findings have suggested the participation of sensory axon collaterals in neurogenic inflammatory responses in other somatic and visceral organs [3, 33, 84, 108] (Fig. 1).

The events, which follow the activation of dural chemosensitive nocisensors, may be regarded as components of a positive feedback regulation, which may generate an 


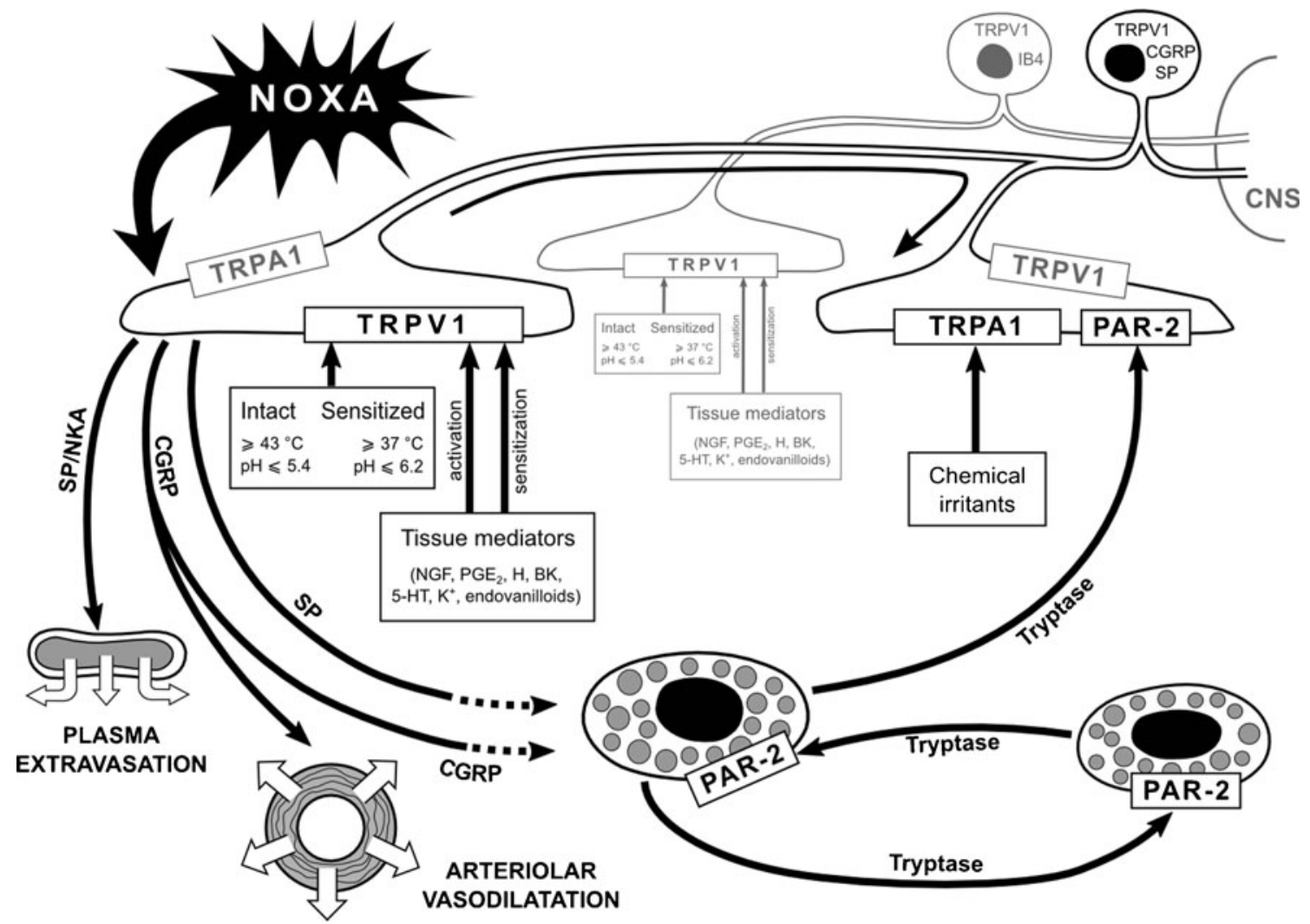

Fig. 1 Functions of the trigeminovascular nocisensor complex. The dural chemosensitive afferent nerves equipped with specific nocisensor molecules, in particular, TRP channels, the elements of the meningeal microcirculatory system, and the dural mast cells comprise the components of the trigeminovascular nocisensor complex. Stimulation of dural nociceptors by noxious agents results in the parallel transmission of nociceptive signals toward the central nervous system through peptidergic and non-peptidergic (IB4-positive) primary sensory neurons. Importantly, peptidergic nerves also release the vasoactive peptides CGRP and SP if stimulated, which produce vasodilatation and plasma extravasation, respectively. Stimulated nociceptors may also activate other nociceptive endings through an axon reflex mechanism (curved arrow). A variety of tissue mediators may excite or sensitize

exaggeration of the initial nociceptive and vascular responses. This assumption is in line with clinical observations showing a significant worsening of the initial symptoms in the course of a migraine attack. The mechanisms leading to the initiation of the migraine attack are, at present, as enigmatic as the mechanisms operating at the cessation of the headache pain.

Considering the available experimental evidence, a concept of a trigeminovascular nocisensor complex is proposed. It is further suggested that the peripheral mechanisms participating in the initiation, maintenance, and cessation of head pain may be explained in the frame of this concept.

The elements of this complex include the trigeminovascular chemosensitive primary afferent neuron with its peripheral and central processes, the meningeal vascular bed, and the dural mast cells. It is suggested that the elements of this complex are both anatomically and functionally intimately the TRP channels, which may also be sensitized through the activation of PAR-2 receptors by mast cell tryptase. Mast cells may be activated by CGRP and SP released from the nociceptor terminals and also by mast cell tryptase. Available evidence suggests a mutual activation of mast cells through the PAR-2 receptor, which provides a possibility for a self-triggering mechanism of mast cells resulting in an augmentation of the primary response. For further details, see text. $B K$ bradykinin, $C G R P$ calcitonin gene-related peptide, 5-HT serotonin, IB4 G. simplicifolia isolectin $\mathrm{B} 4, N K A$ neurokinin A, $P A R-2$ proteinase-activated receptor-2, $P G E 2$ prostaglandin E2, $S P$ substance $\mathrm{P}, T R P A 1$ transient receptor potential ankyrin $1, T R P V 1$ transient receptor potential vanilloid 1, NGF nerve growth factor, $H$ histamine, $C N S$ central nervous system

interconnected and may be regarded as an important physiological and pathophysiological entity. Morphological studies furnished evidence for the close association of meningeal sensory nerves with blood vessels and also with mast cells [46]. Activation and sensitization of meningeal nociceptors by a variety of blood- and tissue-born inflammatory agents is the most important peripheral mechanism in the initiation of a migraine attack [51]. Some of these agents may act on their specific receptors expressed on nociceptors, whereas others may activate the TRPV1 and TRPA1 ion channels. The biochemical pathways for the activation of these specific nociceptive channels are now well established [93].

The activated nociceptor nerves transmit nociceptive impulses toward the central nervous system, and they also release vasoactive peptides, which exert their effect on neighboring blood vessels. CGRP causes vasodilatation whereas SP/ 
NKA may cause an increase in vascular (mainly postcapillary venular) permeability, i.e., a neurogenic inflammatory response [24, 114]. In addition, these vasoactive peptides also induce mast cell activation resulting in the release of mast cell mediators, such as histamine and mast cell tryptase [30]. These, in turn, may activate receptors of the nociceptive nerve terminals resulting in further neuropeptide release that strongly amplifies the initial vascular reaction and possibly also the central transmission of the nociceptive signal. The primary reaction is further augmented through the sensitization of nociceptors by inflammatory mediators, including nerve growth factor, and also by the activation of PAR-2 receptors. Sensitization of meningeal nociceptors through the activation of PAR-2 receptors co-expressed with the TRPV1 receptors in chemosensitive afferents has been revealed recently [36]. This observation is particularly interesting in the light of a selfamplification mechanism of mast cell degranulation through which mast cells may amplify their own activation-degranulation signals in an autocrine or paracrine manner [55]. The available data of human studies and animal experiments suggest that many facets of the peripheral pathomechanisms of head pain may be explained in the frame of the proposed concept of the trigeminovascular nocisensor complex. The elements of this system function in a concerted manner to initiate and to maintain and augment the vascular and nociceptive responses associated with migraine headaches, e.g., through blood, tissue, and nociceptor-born inflammatory mediators, and through nocisensor sensitization and mast cell (auto)activation, respectively. TRPV1 and TRPA1 receptors expressed by chemosensitive afferent neurons play a pivotal role in the functioning of the trigeminovascular nocisensor complex through both the central transmission of nociceptive signals and the peripheral release of vasoactive neuropeptides synthesized and transported in a peripherally regulated manner to their endings in the dura mater. Considering the changes in the levels of CGRP in the jugular blood of humans during migraine headache [52] and the decreased dural CGRP levels after prolonged electrical stimulation of trigeminal afferents $[74,111]$, it is tempting to suggest that depletion of the peptide from dural afferent nerves and the consequent decreased activation level of the trigeminovascular nocisensor complex may be related to the cessation of head pain. In addition, neurogenic sensory vasodilatation may have also beneficial effects by removing tissue metabolites inducing or aggravating headache attacks [34, 35, 37].

\section{Inhaled environmental irritants induce headache through the activation of TRPA1}

The TRPA1 ion channel, another member of the TRP receptor superfamily, has emerged recently as possibly the most important receptor activated by noxious chemical agents including environmental irritants [7]. The expression of TRPA1 has been also demonstrated in a population of trigeminal nociceptive neurons [71]. TRPA1 receptors can be activated by noxious cold, different environmental electrophyl irritants like acrolein and formaldehyde and also by pungent ingredients of plant origin, like cinnamaldehyde and allyl isothiocyanate [4, 66, 85, 123]. Hydrogen peroxide, 4-hydroxylnonenal, and a prostaglandin metabolite produced endogenously in sensory ganglion cells excite the TRPA1 receptor $[15,25]$. Both exogenous and endogenous activators of the TRPA1 modify cysteine residues of the receptor by the formation of either covalent or not covalent bonds [86, 126]. In susceptible persons asthma, allergic rhinitis, and headache attacks are well-known consequences of exposure to environmental irritants. Recent findings furnished direct evidence for the involvement of TRPA1 receptors in headache mechanisms in humans by showing that umbellulone, the major volatile constituent of the "headache tree", Umbellularia californica, provokes headaches through the activation of the TRPA1 receptor [96]. Similarly to TRPV1, activation of trigeminovascular afferents through TRPA1 receptors causes nociceptive responses and the release of CGRP in rodents. Both nociceptive responses and CGRP release were absent in TRPA1-deficient mice [100]. It has been suggested that a number of irritant agents such as chlorine, cigarette smoke, and formaldehyde triggers head pain through the activation of the TRPA1 channel $[1,8,47$, 88]. This suggestion is supported by immunohistochemical and in situ hybridization findings which revealed that $36 \%$ of the trigeminal sensory ganglion neurons express TRPA1 in rodents. TRPA 1 was present almost exclusively in smalland medium-sized neurons. The overwhelming majority (97\%) of TRPA1-expressing cells contained also the vasoactive neuropeptides CGRP and SP [118]. Double immunostaining of rat sensory ganglion cells revealed that $80 \%$ of TRPA1 imunoreactive neurons also expressed the PAR-2 receptor [27]. This high percentage of coexpression provides a firm morphological basis for the functional cooperation between these receptors. Mast cell tryptase activating the PAR-2 receptor may sensitize not only the TRPV1 but also the TRPA1 receptors of trigeminal afferents. PAR-2-mediated TRPA1 sensitization seems to activate an intracellular mechanism that is independent of the protein kinase $\mathrm{C}$ pathway. Cleavage of PAR-2 may activate phopholipase $\mathrm{C}$ which releases the inhibition of TRPA1 from membrane phosphatidylinositol-4,5-bisphosphate [27].

\section{Interactions of TRPV1 and TRPA1 receptors in trigeminal sensory ganglion cells}

Histological and functional observations have revealed the co-localization of TRPV1 and TRPA1 receptors in both the 
dorsal root $[66,118]$ and the trigeminal $[66,109]$ sensory ganglion neurons. Although the mechanisms of activation of these channels differ significantly, experimental evidence indicates a functional interaction between TRPV1 and TRPA1 receptors which may modify the responses of nociceptive neurons toward the selective chemical activators of these ion channels. By recording mustard-oil-induced ionic currents from Chinese hamster ovary cells co-transfected with TRPA1/TRPV1 mRNAs or trigeminal ganglion neurons isolated from TRPV1 knock-out animals, Salas and coworkers [109] demonstrated that the amplitude, calcium sensitivity, and voltage-dependency of the mustard-oil-induced currents were strongly affected by the presence or absence of the TRPV1 channel. A non-significant difference in the amplitude of the mustard-oil-induced membrane currents between the capsaicin-sensitive and capsaicin-insensitive subpopulations of vagal afferent neurons was also reported [21]. Since mustard oil does not produce a direct activation of TRPV1 receptor at the concentration used in these experiments [43], it was hypothesized that TRPV1 either stabilizes the membrane localization of functional TRPA1 channels or (positively) regulates their sensitivity toward the TRPA1specific chemical irritants [109]. Conversely, TRPA1 channel activation has been shown to restore the capsaicin sensitivity of TRPV1 following desensitization of the channel with repeated brief exposures to capsaicin [130]. Similar synergisms between the TRPV1 and TRPA1 channels might also occur centrally at the medullary termination sites of chemosensitive dural afferents which co-express these TRP channels [54, 69, 123]. Crosstalk between TRP channels might bear of special importance under conditions of receptor sensitization through inflammatory mediators brought about, in part, by posttranslational modifications of the TRP channels $[22,58,83$, 124]. It has been demonstrated that, following sensitization of the TRPV1 channel, the activation threshold for both thermal and chemical stimuli decreases significantly, resulting in the opening of the channel at physiological temperatures [45, 104]. Similarly, endogenous agonists which possess low potency and/or are present at very low tissue concentrations may also activate the sensitized channel $[28,117]$.

\section{TRPV1 and TRPA1 receptors localized in trigeminal afferents innervating extracranial tissues may contribute to meningeal sensory neurogenic vascular reactions and head pain}

Under experimental conditions, capsaicin, mustard oil, and acrolein through the activation of TRPV1 and/or TRPA1 receptors of the nasal mucosa induce meningeal vasodilatation in the rat which is mediated by the release of CGRP from trigeminal perivascular nerves. Although the contribution of a trigemino-parasympathetic reflex increasing meningeal blood flow after noxious chemical stimulation of the facial mucosa cannot be excluded [53], it is very likely that trigeminal afferents that innervate the nasal mucosa project collaterals to meningeal blood vessels. Nociceptive stimulation of extracranial tissues may activate intracranial collaterals by an axon reflex mechanism and release vasoactive neuropeptides in the meningeal tissue. In humans, inhaled irritants may stimulate such extracranial trigeminal afferents that innervate the nasal mucosa and project collaterals also to the meningeal blood vessels [76, 96]. In mice, immunohistochemistry has revealed CGRPimmunoreactive sensory nerve fibres in the emissary canals and sutures of cranial bones that were branches of dural nerves [75]. Activation of such extracranial collaterals of meningeal sensory vasomotor nerve fibers may explain the induction of headache attacks by extracranial triggers, such as tenderness of scalp muscles. The pathophysiological role of the excitation of TRPV1 and TRPA1 receptors that are localized on extracranial collaterals of meningeal trigeminal afferents is further supported by the beneficial effect of botulinum toxin injection into the pericranial muscles for migraine prevention. Botulinum toxin inhibits the release of CGRP, SP, and glutamate from the primary nociceptive neurons, reducing the neurogenic inflammation in the dura mater and the peripheral sensitization of the nociceptors [9, 97]. This may reduce the inflow of nociceptive information to the central nervous system that may inhibit also the central sensitization of neurons in the trigeminal nucleus caudalis [107]. Clinical studies proved that injection of botulinum toxin into pericranial muscles is an effective treatment in the prophylaxis of migraine.

\section{Concluding remarks}

Clinical observations and animal studies provided evidence for a central role of chemosensitive trigeminal afferents, which express the nociceptor ion channels TRPV1 and TRPA1, in the mechanisms of meningeal nociception and headache. Trigeminal chemosensitive primary sensory neurons are comprised of peptidergic and non-peptidergic populations of different functional traits which may serve parallel transmission of the nociceptive information towards the central nervous system. It is suggested that many facets of the peripheral mechanisms of head pain may be explained in the frame of the proposed concept of the trigeminovascular nocisensor complex. The elements of this system function in a concerted manner to initiate and to maintain and augment the vascular, inflammatory, and nociceptive responses associated with migraine headaches, e.g., through blood, tissue, and nociceptor-born inflammatory mediators, and through nocisensor sensitization and mast cell (auto)activation, respectively. TRPV1 and TRPA1 receptors 
expressed by chemosensitive afferent neurons play a pivotal role in the functioning of the trigeminovascular nocisensor complex through both the central transmission of nociceptive signals and peripheral release of vasoactive neuropeptides synthesized and transported in a peripherally regulated manner to their endings in the dura mater. Pharmacological and/or genetic manipulations which selectively eliminate chemosensitive nociceptor afferent nerves and/or interfere with the function of the TRP channels, TRPV1 and TRPA1, may offer new approaches to the further understanding of the pathophysiology of headaches and also for the management of primary headaches, in particular, migraine.

Acknowledgments The authors thank Dr. Ildikó Hajdú for help with preparing the artwork. This work was supported by grants from the Hungarian Scientific Research Fund (OTKA K-101873) and the National Developmental Agency of Hungary (TAMOP 4.2.2/B-10/12010-0012 and 4.2.1/B-09/1/KONV-2010-0005).

\section{References}

1. Andrè E, Campi B, Materazzi S, Trevisani M, Amadesi S, Massi D, Creminon C, Vaksman N, Nassini R, Civelli M, Baraldi PG, Poole DP, Bunnett NW, Geppetti P, Patacchini R (2008) Cigarette smoke-induced neurogenic inflammation is mediated by alpha, beta-unsaturated aldehydes and the TRPA1 receptor in rodents. J Clin Invest 118:2574-2582

2. Andres KH, von Düring M, Muszynski K, Schmidt RF (1987) Nerve fibres and their terminals of the dura mater encephali of the rat. Anat Embryol (Berl) 175:289-301

3. Arvier PT, Chahl LA, Ladd RJ (1977) Modification by capsaicin and compound $48 / 80$ of dye leakage induced by irritants in the rat. Br J Pharmacol 59:61-68

4. Bandell M, Story GM, Hwang SW, Viswanath V, Eid SR, Petrus MJ, Earley TJ, Patapoutian A (2004) Noxious cold ion channel TRPA1 is activated by pungent compounds and bradykinin. Neuron 41:849-857

5. Bartsch T, Goadsby PJ (2003) Increased responses in trigeminocervical nociceptive neurons to cervical input after stimulation of the dura mater. Brain 126(Pt 8):1801-1813

6. Baylie RL, Brayden JE (2011) TRPV channels and vascular function. Acta Physiol (Oxf) 203:99-116

7. Belvisi MG, Dubuis E, Birrell MA (2011) Transient receptor potential A1 channels: insights into cough and airway inflammatory disease. Chest 140:1040-1047

8. Bessac BF, Sivula M, von Hehn CA, Escalera J, Cohn L, Jordt SE (2008) TRPA1 is a major oxidant sensor in murine airway sensory neurons. J Clin Invest 118:1899-1910

9. Blumenfeld A, Evans RW (2012) OnabotulinumtoxinA for chronic migraine. Headache 52:142-148

10. Bolay H, Moskowitz MA (2002) Mechanisms of pain modulation in chronic syndromes. Neurology 59(5 Suppl 2):S2-S7

11. Brain SD (2011) TRPV1 and TRPA1 channels in inflammatory pain: elucidating mechanisms. Ann N Y Acad Sci 1245:36-37

12. Breese NM, George AC, Pauers LE, Stucky CL (2005) Peripheral inflammation selectively increases TRPV1 function in IB4positive sensory neurons from adult mouse. Pain 115:37-49

13. Burstein R, Jakubowski M, Rauch SD (2011) The science of migraine. J Vestib Res 21:305-314
14. Buzzi MG, Bonamini M, Moskowitz MA (1995) Neurogenic model of migraine. Cephalalgia 15:277-280

15. Cao DS, Zhong L, Hsieh TH, Abooj M, Bishnoi M, Hughes L, Premkumar LS (2012) Expression of transient receptor potential ankyrin 1 (TRPA1) and its role in insulin release from rat pancreatic beta cells. PLoS One 7(5):e38005

16. Caterina MJ, Julius D (2001) The vanilloid receptor: a molecular gateway to the pain pathway. Annu Rev Neurosci 24:487-517

17. Caterina MJ, Schumacher MA, Tominaga M, Rosen TA, Levine JD, Julius D (1997) The capsaicin receptor: a heat-activated ion channel in the pain pathway. Nature 389:816-824

18. Cavallotti D, Artico M, De Santis S, Iannetti G, Cavallotti C (1998) Catecholaminergic innervation of the human dura mater involved in headache. Headache 38:352-355

19. Cavanaugh DJ, Chesler AT, Bráz JM, Shah NM, Julius D, Basbaum AI (2011) Restriction of transient receptor potential vanilloid-1 to the peptidergic subset of primary afferent neurons follows its developmental downregulation in nonpeptidergic neurons. J Neurosci 31:10119-10127

20. Chen Y (2009) Advances in the pathophysiology of tension-type headache: from stress to central sensitization. Curr Pain Headache Rep 13:484-494

21. Choi MJ, Jin Z, Park YS, Rhee YK, Jin YH (2011) Transient receptor potential (TRP) A1 activated currents in TRPV1 and cholecystokinin-sensitive cranial visceral afferent neurons. Brain Res 1383:36-42

22. Chuang HH, Prescott ED, Kong H, Shields S, Jordt SE, Basbaum AI, Chao MV, Julius D (2001) Bradykinin and nerve growth factor release the capsaicin receptor from PtdIns(4,5)P2-mediated inhibition. Nature 411:957-962

23. Cortright DN, Szallasi A (2009) The role of the vanilloid and related receptor sin nociceptor function and neuroimmune regulation. In: Jancsó G (ed) Neuroimmune biology, vol 8, 1st edn, Neurogenic Inflammation in Health and Disease. Elsevier, Amsterdam, pp 101-120

24. Couture R, Cuello AC (1984) Studies on the trigeminal antidromic vasodilatation and plasma extravasation in the rat. J Physiol 346:273-285

25. Cruz-Orengo L, Dhaka A, Heuermann RJ, Young TJ, Montana MC, Cavanaugh EJ, Kim D, Story GM (2008) Cutaneous nociception evoked by 15-delta PGJ2 via activation of ion channel TRPA1. Mol Pain 4:30

26. Csont $T$, Csonka $C$, Kovács $P$, Jancsó $G$, Ferdinandy $P$ (2003) Capsaicin-sensitive sensory neurons regulate myocardial nitric oxide and cGMP signaling. Eur J Pharmacol 476:107-113

27. Dai Y, Wang S, Tominaga M, Yamamoto S, Fukuoka T, Higashi T, Kobayashi K, Obata K, Yamanaka H, Noguchi K (2007) Sensitization of TRPA1 by PAR2 contributes to the sensation of inflammatory pain. J Clin Invest 117:1979-1987

28. De Petrocellis L, Chu CJ, Moriello AS, Kellner JC, Walker JM, Di Marzo V (2004) Actions of two naturally occurring saturated $\mathrm{N}$-acyldopamines on transient receptor potential vanilloid 1 (TRPV1) channels. Br J Pharmacol 143:251-256

29. Diener HC, RPR100893 Study Group (2003) RPR100893, a substance-P antagonist, is not effective in the treatment of migraine attacks. Cephalalgia 23:183-185

30. Dimitriadou V, Buzzi MG, Moskowitz MA, Theoharides TC (1991) Trigeminal sensory fiber stimulation induces morphological changes reflecting secretion in rat dura mater mast cells. Neuroscience 44:97-112

31. Donaldson LF, Harmar AJ, McQueen DS, Seckl JR (1992) Increased expression of preprotachykinin, calcitonin gene-related peptide, but not vasoactive intestinal peptide messenger RNA in dorsal root ganglia during the development of adjuvant monoarthritis in the rat. Brain Res Mol Brain Res 16:143-149 
32. Duggan AW, Morton CR, Zhao ZQ, Hendry IA (1987) Noxious heating of the skin releases immunoreactive substance $\mathrm{P}$ in the substantia gelatinosa of the cat: a study with antibody microprobes. Brain Res 403:345-349

33. Dux M, Jancsó G, Sann H, Pierau FK (1996) Inhibition of the neurogenic inflammatory response by lidocaine in rat skin. Inflamm Res 45:10-13

34. Dux M, Sántha P, Jancsó G (2003) Capsaicin-sensitive neurogenic sensory vasodilatation in the dura mater of the rat. J Physiol 552:859-867

35. Dux M, Rosta J, Pintér S, Sántha P, Jancsó G (2007) Loss of capsaicin-induced meningeal neurogenic sensory vasodilatation in diabetic rats. Neuroscience 150:194-201

36. Dux M, Rosta J, Sántha P, Jancsó G (2009) Involvement of capsaicin-sensitive afferent nerves in the proteinase-activated receptor 2-mediated vasodilatation in the rat dura mater. Neuroscience 161:887-894

37. Dux M, Rosta J, Jancsó G (2011) Capsaicin-sensitive nociceptive innervation of the dura mater: implications for the pathomechanism of headache. Anti Inflamm Anti Allergy Agents Med Chem 10:31-42

38. Edvinsson L, Uddman R (1981) Adrenergic, cholinergic and peptidergic nerve fibres in dura mater-involvement in headache? Cephalalgia 1:175-179

39. Edvinsson L, Alm R, Shaw D, Rutledge RZ, Koblan KS, Longmore J, Kane SA (2002) Effect of the CGRP receptor antagonist BIBN4096BS in human cerebral, coronary and omental arteries and in SK-N-MC cells. Eur J Pharmacol 434:49-53

40. Eid SR (2011) Therapeutic targeting of TRP channels - the TR (i)P to pain relief. Curr Top Med Chem 11:2118-2130

41. Elekes K, Helyes Z, Németh J, Sándor K, Pozsgai G, Kereskai L, Börzsei R, Pintér E, Szabó A, Szolcsányi J (2007) Role of capsaicin-sensitive afferents and sensory neuropeptides in endotoxin-induced airway inflammation and consequent bronchial hyperreactivity in the mouse. Regul Pept 141:44-54

42. Escott KJ, Brain SD (1993) Effect of a calcitonin gene-related peptide antagonist (CGRP8-37) on skin vasodilatation and oedema induced by stimulation of the rat saphenous nerve. $\mathrm{Br} \mathrm{J}$ Pharmacol 110:772-776

43. Everaerts W, Gees M, Alpizar YA, Farre R, Leten C, Apetrei A, Dewachter I, van Leuven F, Vennekens R, De Ridder D, Nilius B, Voets T, Talavera K (2011) The capsaicin receptor TRPV1 is a crucial mediator of the noxious effects of mustard oil. Curr Biol 21:316-321

44. Feindel W, Penfield W, McNaughton F (1960) The tentorial nerves and localization of intracranial pain in man. Neurology 10:555-563

45. Fischer MJ, Reeh PW (2007) Sensitization to heat through Gprotein-coupled receptor pathways in the isolated sciatic mouse nerve. Eur J Neurosci 25:3570-3575

46. Fricke B, Andres KH, Von Düring M (2001) Nerve fibers innervating the cranial and spinal meninges: morphology of nerve fiber terminals and their structural integration. Microsc Res Tech 53:96-105

47. Fujita F, Uchida K, Moriyama T, Shima A, Shibasaki K, Inada H, Sokabe T, Tominaga M (2008) Intracellular alkalization causes pain sensation through activation of TRPA1 in mice. J Clin Invest 118:4049-4057

48. Gamse R, Holzer P, Lembeck F (1980) Decrease of substance P in primary afferent neurons and impairment of neurogenic plasma extravasation by capsaicin. Br J Pharmacol 68:207-213

49. Gamse R, Posch M, Saria A, Jancsó G (1987) Several mediators appear to interact in neurogenic inflammation. Acta Physiol Hung 69:343-354

50. Geppetti P, Materazzi S, Nicoletti P (2006) The transient receptor potential vanilloid 1: role in airway inflammation and disease. Eur J Pharmacol 533:207-214
51. Goadsby PJ (2007) Recent advances in understanding migraine mechanisms, molecules and therapeutics. Trends Mol Med 13:39-44

52. Goadsby PJ, Edvinsson L, Ekman R (1990) Vasoactive peptide release in the extracerebral circulation of humans during migraine headache. Ann Neurol 28:183-187

53. Gottselig R, Messlinger K (2004) Noxious chemical stimulation of rat facial mucosa increases intracranial blood flow through a trigemino-parasympathetic reflex - an experimental model for vascular dysfunctions in cluster headache. Cephalalgia 24:206214

54. Gregus AM, Doolen S, Dumlao DS, Buczynski MW, Takasusuki T, Fitzsimmons BL, Hua XY, Taylor BK, Dennis EA, Yaksh TL (2012) Spinal 12-lipoxygenase-derived hepoxilin A3 contributes to inflammatory hyperalgesia via activation of TRPV1 and TRPA1 receptors. Proc Natl Acad Sci U S A 109:6721-6726

55. He SH (2004) Key role of mast cells and their major secretory products in inflammatory bowel disease. World J Gastroenterol 10:309-318

56. Hökfelt T, Johansson O, Ljungdahl A, Lundberg JM, Schultzberg M (1980) Peptidergic neurones. Nature 284:515-521

57. Imamura K, Takeshima T, Fusayasu E, Nakashima K (2008) Increased plasma matrix metalloproteinase- 9 levels in migraineurs. Headache 48:135-139

58. Immke DC, Gavva NR (2006) The TRPV1 receptor and nociception. Semin Cell Dev Biol 17:582-591

59. Jancsó G, Király E (1980) Distribution of chemosensitive primary sensory afferents in the central nervous system of the rat. $\mathrm{J}$ Comp Neurol 190:781-792

60. Jancsó N, Jancsó-Gábor A, Szolcsányi J (1967) Direct evidence for neurogenic inflammation and its prevention by denervation and by pretreatment with capsaicin. Br J Pharmacol Chemother 31:138-151

61. Jancsó G, Király E, Jancsó-Gábor A (1977) Pharmacologically induced selective degeneration of chemosensitive primary sensory neurones. Nature $270: 741-743$

62. Jancsó G, Hökfelt T, Lundberg JM, Kiraly E, Halász N, Nilsson G, Terenius L, Rehfeld J, Steinbusch H, Verhofstad A, Elde R, Said S, Brown M (1981) Immunohistochemical studies on the effect of capsaicin on spinal and medullary peptide and monoamine neurons using antisera to substance $\mathrm{P}$, gastrin/CCK, somatostatin, VIP, enkephalin, neurotensin and 5-hydroxytryptamine. J Neurocytol 10:963-980

63. Jancsó G, Obál F Jr, Tóth-Kása I, Katona M, Husz S (1985) The modulation of cutaneous inflammatory reactions by peptidecontaining sensory nerves. Int J Tissue React 7:449-457

64. Jancsó G, Katona M, Horváth V, Sántha P, Nagy J (2009) Sensory nerves as modulators of cutaneous inflammatory reactions in health and disease. In: Jancsó G (ed) Neuroimmune biology, vol 8,1 st edn, Neurogenic Inflammation in Health and Disease. Elsevier, Amsterdam, pp 3-38

65. Johnson AR, Erdös EG (1973) Release of histamine from mast cells by vasoactive peptides. Proc Soc Exp Biol Med 142:12521256

66. Jordt SE, Bautista DM, Chuang HH, McKemy DD, Zygmunt PM, Högestätt ED, Meng ID, Julius D (2004) Mustard oils and cannabinoids excite sensory nerve fibres through the TRP channel ANKTM1. Nature 427:260-265

67. Julius D, Basbaum AI (2001) Molecular mechanisms of nociception. Nature 413:203-210

68. Katona M, Boros K, Sántha P, Ferdinandy P, Dux M, Jancsó G (2004) Selective sensory denervation by capsaicin aggravates adriamycininduced cardiomyopathy in rats. Naunyn Schmiedeberg's Arch Pharmacol 370:436-443

69. Katsura H, Obata K, Mizushima T, Sakurai J, Kobayashi K, Yamanaka H, Dai Y, Fukuoka T, Sakagami M, Noguchi K 
(2006) Activation of Src-family kinases in spinal microglia contributes to mechanical hypersensitivity after nerve injury. J Neurosci 26:8680-8690

70. Keller JT, Marfurt CF, Dimlich RV, Tierney BE (1989) Sympathetic innervation of the supratentorial dura mater of the rat. $\mathrm{J}$ Comp Neurol 290:310-321

71. Kim YS, Son JY, Kim TH, Paik SK, Dai Y, Noguchi K, Ahn DK, Bae YC (2010) Expression of transient receptor potential ankyrin 1 (TRPA1) in the rat trigeminal sensory afferents and spinal dorsal horn. J Comp Neurol 518:687-698

72. Király E, Jancsó G, Hajós M (1991) Possible morphological correlates of capsaicin desensitization. Brain Res 540:279-282

73. Knotkova H, Pappagallo M, Szallasi A (2008) Capsaicin (TRPV1 agonist) therapy for pain relief: farewell or revival? Clin J Pain 24:142-154

74. Knyihár-Csillik E, Tajti J, Samsam M, Sáry G, Buzás P, Vécsei L (1998) Depletion of calcitonin gene-related peptide from the caudal trigeminal nucleus of the rat after electrical stimulation of the Gasserian ganglion. Exp Brain Res 118:111-114

75. Kosaras B, Jakubowski M, Kainz V, Burstein R (2009) Sensory innervation of the calvarial bones of the mouse. J Comp Neurol 515:331-348

76. Kunkler PE, Ballard CJ, Oxford GS, Hurley JH (2011) TRPA1 receptors mediate environmental irritant-induced meningeal vasodilatation. Pain 152:38-44

77. Kurosawa M, Messlinger K, Pawlak M, Schmidt RF (1995) Increase of meningeal blood flow after electrical stimulation of rat dura mater encephali: mediation by calcitonin gene-related peptide. Br J Pharmacol 114:1397-1402

78. Lauritzen M (1994) Pathophysiology of the migraine aura. The spreading depression theory. Brain 117(Pt 1):199-210

79. Lawson SN, Perry MJ, Prabhakar E, McCarthy PW (1993) Primary sensory neurones: neurofilament, neuropeptides, and conduction velocity. Brain Res Bull 30:239-243

80. Levy D, Strassman AM, Burstein R (2009) A critical view on the role of migraine triggers in the genesis of migraine pain. Headache 49:953-957

81. Li WW, Guo TZ, Liang DY, Sun Y, Kingery WS, Clark JD (2012) Substance P signaling controls mast cell activation, degranulation, and nociceptive sensitization in a rat fracture model of complex regional pain syndrome. Anesthesiology 116:882-895

82. Liu M, Willmott NJ, Michael GJ, Priestley JV (2004) Differential $\mathrm{pH}$ and capsaicin responses of Griffonia simplicifolia IB4 (IB4)positive and IB4-negative small sensory neurons. Neuroscience 127:659-672

83. Lopshire JC, Nicol GD (1998) The cAMP transduction cascade mediates the prostaglandin E2 enhancement of the capsaicinelicited current in rat sensory neurons: whole-cell and singlechannel studies. J Neurosci 18:6081-6092

84. Lundberg JM, Saria A (1983) Capsaicin-induced desensitization of airway mucosa to cigarette smoke, mechanical and chemical irritants. Nature 302:251-253

85. Macpherson LJ, Geierstanger BH, Viswanath V, Bandell M, Eid SR, Hwang S, Patapoutian A (2005) The pungency of garlic: activation of TRPA1 and TRPV1 in response to allicin. Curr Biol 15:929-934

86. Macpherson LJ, Dubin AE, Evans MJ, Marr F, Schultz PG, Cravatt BF, Patapoutian A (2007) Noxious compounds activate TRPA1 ion channels through covalent modification of cysteines. Nature 445:541-545

87. Maggi CA, Meli A (1988) The sensory-efferent function of capsaicin-sensitive sensory neurons. Gen Pharmacol 19:1-43

88. McNamara CR, Mandel-Brehm J, Bautista DM, Siemens J, Deranian KL, Zhao M, Hayward NJ, Chong JA, Julius D, Moran MM, Fanger CM (2007) TRPA1 mediates formalininduced pain. Proc Natl Acad Sci U S A 104:13525-13530
89. Meents JE, Neeb L, Reuter U (2010) TRPV1 in migraine pathophysiology. Trends Mol Med 16:153-159

90. Messlinger K, Ellrich J (2001) Meningeal nociception: electrophysiological studies related to headache and referred pain. Microsc Res Tech 53:129-137

91. Messlinger K, Hanesch U, Baumgärtel M, Trost B, Schmidt RF (1993) Innervation of the dura mater encephali of cat and rat: ultrastructure and calcitonin gene-related peptide-like and substance P-like immunoreactivity. Anat Embryol 188:219-237

92. Mione MC, Cavanagh JFR, Kirkpatrick KA, Burnstock G (1992) Plasticity in expression of calcitonin gene-related peptide and substance $\mathrm{P}$ immunoreactivity in ganglia and fibres following guanethidine and/or capsaicin denervation. Cell Tissue Res 268:491-504

93. Mizumura K, Sugiura T, Katanosaka K, Banik RK, Kozaki Y (2009) Excitation and sensitization of nociceptors by bradykinin: what do we know? Exp Brain Res 196:53-65

94. Moreno MJ, Abounader R, Hébert E, Doods H, Hamel E (2002) Efficacy of the non-peptide CGRP receptor antagonist BIBN4096BS in blocking CGRP-induced dilations in human and bovine cerebral arteries: potential implications in acute migraine treatment. Neuropharmacology 42:568-576

95. Nagy I, Sántha P, Jancsó G, Urbán L (2004) The role of the vanilloid (capsaicin) receptor (TRPV1) in physiology and pathology. Eur J Pharmacol 500:351-369

96. Nassini R, Materazzi S, Vriens J, Prenen J, Benemei S, De Siena G, la Marca G, Andrè E, Preti D, Avonto C, Sadofsky L, Di Marzo V, De Petrocellis L, Dussor G, Porreca F, TaglialatelaScafati O, Appendino G, Nilius B, Geppetti P (2012) The 'headache tree' via umbellulone and TRPA1 activates the trigeminovascular system. Brain 135(Pt 2):376-390

97. Negro A, Rocchietti-March M, Fiorillo M, Martelletti P (2011) Chronic migraine: current concepts and ongoing treatments. Eur Rev Med Pharmacol Sci 15:1401-1420

98. Nilius B, Owsianik G, Voets T, Peters JA (2007) Transient receptor potential cation channels in disease. Physiol Rev 87:165-217

99. Nozaki K, Moskowitz MA, Boccalini P (1992) CP-93,129, sumatriptan, dihydroergotamine block c-fos expression within rat trigeminal nucleus caudalis caused by chemical stimulation of the meninges. Br J Pharmacol 106:409-415

100. Ogawa H, Takahashi K, Miura S, Imagawa T, Saito S, Tominaga M, Ohta T (2012) H(2)S functions as a nociceptive messenger through transient receptor potential ankyrin 1 (TRPA1) activation. Neuroscience 218:335-343

101. Olesen J, Diener HC, Husstedt IW, Goadsby PJ, Hall D, Meier U, Pollentier S, Lesko LM, BIBN 4096 BS Clinical Proof of Concept Study Group (2004) Calcitonin gene-related peptide receptor antagonist BIBN 4096 BS for the acute treatment of migraine. N Engl J Med 350:1104-1110

102. Penfield W, McNaughton FL (1940) Dural headache and innervation of the dura mater. Arch Neurol Psychiatr 44:43-75

103. Pernow B (1985) Role of tachykinins in neurogenic inflammation. J Immunol 135(2 Suppl):812s-815s

104. Pethö G, Derow A, Reeh PW (2001) Bradykinin-induced nociceptor sensitization to heat is mediated by cyclooxygenase products in isolated rat skin. Eur J Neurosci 14:210-218

105. Price TJ, Flores CM (2007) Critical evaluation of the colocalization between calcitonin gene-related peptide, substance $P$, transient receptor potential vanilloid subfamily type 1 immunoreactivities, and isolectin B4 binding in primary afferent neurons of the rat and mouse. J Pain 8:263-272

106. Ray BS, Wolff HG (1940) Experimental studies on headache. Pain sensitive structures of the head and their significance in headache. Arch Surg 41:813-856

107. Robertson CE, Garza I (2012) Critical analysis of the use of onabotulinumtoxinA (botulinum toxin type A) in migraine. Neuropsychol Dis Treat 8:35-48 
108. Rózsa Z, Sharkey KA, Jancsó G, Varró V (1986) Evidence for a role of capsaicin-sensitive mucosal afferent nerves in the regulation of mesenteric blood flow in the dog. Gastroenterology 90:906-910

109. Salas MM, Hargreaves KM, Akopian AN (2009) TRPA1mediated responses in trigeminal sensory neurons: interaction between TRPA1 and TRPV1. Eur J Neurosci 29:1568-1578

110. Salvatore CA, Hershey JC, Corcoran HA, Fay JF, JohnstonVK MEL, Mosser SD, Burgey CS, Paone DV, Shaw AW, Graham SL, Vacca JP, Williams TM, Koblan KS, Kane SA (2008) Pharmacological characterization of MK-0974 [N-[(3R,6S)-6-(2,3-difluorophenyl)-2-oxo-1-(2,2,2-trifluoroethyl)azepan-3-yl]-4-(2-oxo2,3-dihydro- $1 \mathrm{H}$-imidazo[4,5-b]pyridin-1-yl)piperidine-1-carboxamide], a potent and orally active calcitonin gene-related peptide receptor antagonist for the treatment of migraine. J Pharmacol Exp Ther 324:416-421

111. Samsam M, Coveñas R, Csillik B, Ahangari R, Yajeya J, Riquelme R, Narváez JA, Tramu G (2001) Depletion of substance $\mathrm{P}$, neurokinin A and calcitonin gene-related peptide from the contralateral and ipsilateral caudal trigeminal nucleus following unilateral electrical stimulation of the trigeminal ganglion; a possible neurophysiological and neuroanatomical link to generalized head pain. J Chem Neuroanat 21:161-169

112. Sann H, Pierau FK (1998) Efferent functions of C-fiber nociceptors. Z Rheumatol 57(Suppl 2):8-13

113. Sántha P, Oszlács O, Dux M, Dobos I, Jancsó G (2010) Inhibition of glucosylceramide synthase reversibly decreases the capsaicininduced activation and TRPV1 expression of cultured dorsal root ganglion neurons. Pain 150:103-112

114. Saria A, Lundberg JM, Skofitsch G, Lembeck F (1983) Vascular protein linkage in various tissue induced by substance P, capsaicin, bradykinin, serotonin, histamine and by antigen challenge. Naunyn Schmiedeberg's Arch Pharmacol 324:212-218

115. Shimazawa M, Hara H (1996) An experimental model of migraine with aura: cortical hypoperfusion following spreading depression in the awake and freely moving rat. Clin Exp Pharmacol Physiol 23:890-892

116. Shimizu T, Toriumi H, Sato H, Shibata M, Nagata E, Gotoh K, Suzuki N (2007) Distribution and origin of TRPV1 receptorcontaining nerve fibers in the dura mater of rat. Brain Res 1173:84-91

117. Singh Tahim A, Sántha P, Nagy I (2005) Inflammatory mediators convert anandamide into a potent activator of the vanilloid type 1 transient receptor potential receptor in nociceptive primary sensory neurons. Neuroscience 136:539-548

118. Story GM, Peier AM, Reeve AJ, Eid SR, Mosbacher J, Hricik TR, Earley TJ, Hergarden AC, Andersson DA, Hwang SW,
McIntyre P, Jegla T, Bevan S, Patapoutian A (2003) ANKTM1, a TRP-like channel expressed in nociceptive neurons, is activated by cold temperatures. Cell 112:819-829

119. Strassman AM, Levy D (2006) Response properties of dural nociceptors in relation to headache. J Neurophysiol 95:12981306

120. Strassman AM, Mason P, Moskowitz MA, Maciewicz RJ (1986) Response of brainstem trigeminal neurons to electrical stimulation of the dura. Brain Res 379:242-250

121. Strassman AM, Raymond SA, Burstein R (1996) Sensitization of meningeal sensory neurons and the origin of headaches. Nature 384:560-564

122. Tröltzsch M, Denekas T, Messlinger K (2007) The calcitonin gene-related peptide (CGRP) receptor antagonist BIBN4096BS reduces neurogenic increases in dural blood flow. Eur J Pharmacol 562:103-110

123. Uta D, Furue H, Pickering AE, Rashid MH, Mizuguchi-Takase H, Katafuchi T, Imoto K, Yoshimura M (2010) TRPA1-expressing primary afferents synapse with a morphologically identified subclass of substantia gelatinosa neurons in the adult rat spinal cord. Eur J Neurosci 31:1960-1973

124. Vellani V, Mapplebeck S, Moriondo A, Davis JB, McNaughton PA (2001) Protein kinase $C$ activation potentiates gating of the vanilloid receptor VR1 by capsaicin, protons, heat and anandamide. J Physiol 534(Pt 3):813-825

125. von Düring M, Bauersachs M, Böhmer B, Veh RW, Andres KH (1990) Neuropeptide Y- and substance P-like immunoreactive nerve fibers in the rat dura mater encephali. Anat Embryol (Berl) 182:363-373

126. Wang L, Cvetkov TL, Chance MR, Moiseenkova-Bell VY (2012) Identification of in vivo disulfide conformation of TRPA1 ion channel. J Biol Chem 287:6169-6176

127. Williamson DJ, Hargreaves RJ (2001) Neurogenic inflammation in the context of migraine. Microsc Res Tech 53:167-178

128. Zhang XC, Levy D (2008) Modulation of meningeal nociceptors mechanosensitivity by peripheral proteinase-activated receptor-2: the role of mast cells. Cephalalgia 28:276-284

129. Zhang X, Levy D, Noseda R, Kainz V, Jakubowski M, Burstein R (2010) Activation of meningeal nociceptors by cortical spreading depression: implications for migraine with aura. J Neurosci 30:8807-8814

130. Zhang H, Wickley PJ, Sinha S, Bratz IN, Damron DS (2011) Propofol restores transient receptor potential vanilloid receptor subtype-1 sensitivity via activation of transient receptor potential ankyrin receptor subtype-1 in sensory neurons. Anesthesiology 114:1169-1179 